\title{
SELEÇÃO PARA PRODUTIVIDADE DE GRÃOS, ADAPTABILIDADE E ESTABILIDADE DE SORGO GRANÍFERO
}

\author{
KARLA JORGE DA SILVA ${ }^{1}$, CICERO BESERRA DE MENEZES ${ }^{2}$, FLÁVIO DESSAUNE TARDIN², \\ ADELMO RESENDE DA SILVA ${ }^{2}$, MILTON JOSE CARDOSO ${ }^{3}$, EDSON ALVES BASTOS ${ }^{3}$ \\ e VICENTE DE PAULO CAMPOS GODINHO ${ }^{4}$
}

\author{
${ }^{1}$ Universidade Federal de Viçosa, Viçosa, MG, Brasil-karla.js@hotmail.com \\ ${ }^{2}$ Embrapa Milho e Sorgo, Sete Lagoas, MG, Brasil - cicero.menezes@embrapa.br, \\ flavio.tardin@embrapa.br,adelmo.silva@embrapa.br, \\ 3Embrapa Meio Norte, Teresina, PI, Brasil-milton.cardoso@embrapa.br,edson.bastos@embrapa.br \\ ${ }^{4}$ Embrapa Rondônia, Rondônia, RO,Brasil-vicente.godinho@embrapa.br
}

Revista Brasileira de Milho e Sorgo, v.15, n.2, p. 335-345, 2016

\begin{abstract}
RESUMO - Para recomendação dos genótipos adequados para as regiões de cultivo, o estudo da adaptabilidade e da estabilidade dos genótipos é imprescindível nos programas de melhoramento de plantas. O objetivo deste trabalho foi selecionar genótipos de sorgo granífero com adaptabilidade e estabilidade produtiva a diversas regiões brasileiras e verificar a associação entre os métodos de Lin \& Binns (1988), Wricke (1965), Annicchiarico (1992) e Zobel et al. (1988). Os experimentos foram conduzidos em oito ambientes produtores dessa cultura, sob delineamento de blocos ao acaso com três repetições. Foram avaliados 25 genótipos, sendo 23 pertencentes ao programa de melhoramento da Embrapa Milho e Sorgo e dois híbridos comerciais. Os dados de produtividade de grãos foram submetidos à análise conjunta e, após verificar interação genótipos x ambientes significativa, foram realizadas análises de adaptabilidade e estabilidade utilizando os métodos Lin \& Binns (1988), Wricke (1965), Annicchiarico (1992) e Zobel et al. (1988). Os métodos de Annicchiarico (1992) e Lin \& Binns (1988) foram concordantes entre si. A associação relativamente fraca do método AMMI com Wricke (1965) e Annicchiarico (1992) permite o uso combinado desses métodos em estudos de estabilidade e adaptabilidade. Os híbridos 1170036, 1167048 e 1170064 se destacaram por possuírem desempenho superior, alta adaptabilidade e estabilidade e podem ser alternativas para futura recomendação para cultivo.

Palavras-chave: Sorghum bicolor; interação genótipos x ambientes, metodologias não paramétricas.
\end{abstract}

\section{SELECTION OF GRAIN SORGHUM FOR GRAIN PRODUCTIVITY, ADAPTABILITY AND STABILITY}

\begin{abstract}
Studies regarding adaptability and stability of genotypes are essential to plant breeding programs aiming the recommendation of the appropriate genotypes for different growing regions. The objective of this work was to select sorghum grain genotypes with adaptability and stability in various regions of Brazil and to verify the association between the methods of Lin \& Binns (1988), Wricke (1965), Annicchiarico (1992) and Zobel et al. (1988). The experiments were conducted in eight sorghum producing regions, using a randomized blocks design with three replications. Twenty five genotypes were evaluated, 23 belonging to the Embrapa Maize and Sorghum breeding program and two commercial hybrids. The grain yield data were submitted to joint analysis and, after checking significant interaction genotype $\mathrm{x}$ environments, analysis of adaptability and stability were performed using the methods of Lin \& Binns (1988), Wricke (1965), Annicchiarico (1992) and Zobel et al. (1988). The methods Annicchiarico (1992) and Lin and Binns (1988) were concordant. The relatively weak association between the AMMI method and Wricke (1965) and Annicchiarico (1992) allows the combined use of these methods in studies on stability and adaptability. The hybrids 1170036, 1167048 and 1170064 presented superior performance, high adaptability and stability, and thus can be alternatives for future recommendation for cultivation.
\end{abstract}

Keywords: Sorghum bicolor; genotype x environment interaction; nonparametric methods. 
A planta do sorgo adapta-se a uma gama de ambientes, alguns dos quais desfavoráveis à maioria dos cereais, como ambientes com deficiência hídrica e alta temperatura. Essa rusticidade tem possibilitado sua expansão em regiões com distribuição irregular de chuvas e em sucessão a culturas de verão (Santos et al., 2005; Rooney, 2007). Nos programas de melhoramento, é de extrema importância estudar o desempenho dos híbridos em vários ambientes, para selecionar aqueles mais adaptados e estáveis. Assim, no estágio final de um programa de melhoramento, torna-se fundamental a avaliação do comportamento dos genótipos em vários anos e locais (Oliveira et al., 2002). O uso de cultivares adaptadas aos sistemas de produção e às condições ambientais da região de cultivo, além do manejo adequado da cultura, constitui fator importante para a maximização do rendimento de grãos.

Dessa forma, é comum existir interação genótipos $\mathrm{x}$ ambientes $(\mathrm{G} \times \mathrm{A})$ significativa nos estágios finais do programa de melhoramento. As análises de adaptabilidade e estabilidade são, portanto, procedimentos estatísticos que permitem identificar as cultivares de comportamento mais estável e que respondem previsivelmente às variações ambientais (Cruz \& Carneiro, 2003). Desta forma, a estimação dos parâmetros de adaptabilidade e estabilidade fenotípica tem sido uma forma muito difundida entre os melhoristas de plantas (Ramalho et al., 2012) e, atualmente, existe uma vasta gama de métodos disponíveis na literatura.

A possibilidade de utilização de um ou mais parâmetros de estabilidade obtidos por diferentes metodologias para a predição do comportamento de um genótipo frente às variações ambientais exige o estabelecimento do nível de associação entre estas estimativas. De acordo com os parâmetros de adaptabilidade e estabilidade, quando acontece concordância entre os métodos, é possível escolher o que disponibiliza melhor interpretação e facilidade na realização. Porém, caso haja discrepância entre os métodos, a escolha dos melhores genótipos passa a depender do método utilizado, havendo necessidade de escolha do método mais apropriado (Cruz \& Carneiro, 2003).

Nesse sentido, o objetivo deste trabalho foi selecionar genótipos de sorgo granífero com adaptabilidade e estabilidade produtiva a diversas regiões brasileiras e verificar a associação entre os métodos de Lin \& Binns (1988), Wricke (1965), Annicchiarico (1992) e Zobel et al. (1988).

\section{Material e Métodos}

Os experimentos foram conduzidos em regiões distintas, sendo: um em Mata Roma, no Leste maranhense; um em Santo Antônio de Goiás, localizada no Centro de Goiás; dois no Sudoeste goiano, em Rio Verde e Montividiu; Sinop, no Norte mato-grossense; dois no estado de Minas Gerais, conduzidos em Sete Lagoas, localizada na região Central, e em São Gotardo, no Triângulo Mineiro; e na cidade de Vilhena, no Leste rondoniense (Tabela 1). Nos municípios avaliados, existem consideráveis variações geográficas e com distintas condições ambientais.

As parcelas experimentais foram compostas por quatro linhas de $5 \mathrm{~m}$, com espaçamento de $0,5 \mathrm{~m}$ entrelinhas, sendo que apenas as duas fileiras centrais foram consideradas como parcela útil, em delineamento de blocos ao acaso, com três repetições. Foram plantadas duas linhas com híbridos comerciais paralelas aos blocos, com distância de 0,5 m dos mesmos, para servir de bordadura às parcelas experimentais dos blocos.

Foram avaliados 25 híbridos em fase de avaliação de sorgo granífero [Sorghum bicolor (L.) Moen- 
Tabela 1. Descrição geográfica dos municípios onde foram implantados os experimentos.

\begin{tabular}{lccc}
\hline \multicolumn{1}{c}{ Ambientes } & Latitude (S) & Longitude (O) & Altitude (m) \\
\hline Santo Antônio de Goiás - GO & $16^{\circ} 40^{\prime} 00^{\prime \prime}$ & $49^{\circ} 15^{\prime} 00^{\prime \prime}$ & 749 \\
Mata Roma - MA & $03^{\circ} 42^{\prime} 00^{\prime \prime}$ & $43^{\circ} 11^{\prime} 00^{\prime \prime}$ & 127 \\
Rio Verde - MT & $18^{\circ} 55^{\prime} 05^{\prime \prime}$ & $54^{\circ} 50^{\prime} 39^{\prime \prime}$ & 330 \\
Montividiu - GO & $17^{\circ} 26^{\prime} 39^{\prime \prime}$ & $51^{\circ} 10^{\prime} 29^{\prime \prime}$ & 833 \\
Sinop - MT & $11^{\circ} 50^{\prime} 53^{\prime \prime}$ & $55^{\circ} 38^{\prime} 57^{\prime \prime}$ & 384 \\
Sete Lagoas - MG & $19^{\circ} 27^{\prime} 57^{\prime \prime}$ & $44^{\circ} 14^{\prime} 49^{\prime \prime}$ & 767 \\
São Gotardo - MG & $19^{\circ} 18^{\prime} 40^{\prime \prime}$ & $46^{\circ} 02^{\prime} 56^{\prime \prime}$ & 1,100 \\
Vilhena - RO & $12^{\circ} 44^{\prime} 26^{\prime \prime}$ & $60^{\circ} 08^{\prime} 45^{\prime \prime}$ & 615 \\
\hline
\end{tabular}

Fonte: IBGE (2014).

ch], safra 2012/2013, sendo 23 pertencentes ao programa de melhoramento da Embrapa Milho e Sorgo e dois híbridos comerciais (BRS 330 e DKB 550). Os genótipos avaliados foram 0307001, 0307063, 1167026, 0307131, 0307651, 1167052, 0843009, 0306037, 1096019, 0307699, 1168092, 1168093, 0729033, 1170093, 1167048, 1167053, 1167092, 1167093, 1170019, 1170064, 1170090, 1170036, 1170026 , BRS330 e DKB550.

As adubações de plantio e de cobertura foram realizadas com base nas análises de solo e os tratos culturais e fitossanitários de acordo com a necessidade da cultura e de cada região. A característica produtividade de grãos (peso de grãos da área útil, a qual foi trilhada, e corrigiu-se a umidade desses grãos para $13 \%$ e foi transformado para $\mathrm{tha}^{-1}$ ) foi avaliada em oito locais.

Inicialmente, foram realizadas análises individuais de variância, seguindo-se uma análise conjunta de variância para a avaliação da interação genótipos $\mathrm{x}$ ambientes, das características avaliadas nos determinados locais. A natureza do modelo considerou genótipos e ambientes com efeito fixo.

Para verificar a classificação dos ambientes em favoráveis e desfavoráveis, foi calculado o índice ambiental pra cada ambiental. O índice ambiental é a diferença entre a média geral do ambiente e a média geral de todos os ambientes e classifica o ambiente como favorável quando o índice é positivo e desfavorável quando é negativo.

Para determinação da análise de adaptabilidade e estabilidade, avaliou-se a característica produtividade de grãos, utilizando os métodos de Annicchiarico (1992), Lin \& Binns (1988), Wricke (1965) e Zobel et al. (1988).

O método de Annicchiarico propõe a análise da estabilidade por um índice de confiança $\left(\mathrm{W}_{\mathrm{i}}\right)$ de um determinado genótipo apresentar desempenho, relativamente, superior à média do ambiente. $\mathrm{O}$ índice de recomendação pode ser indicado aos ambientes favoráveis ou desfavoráveis, considerando as médias e os desvios respectivos a cada tipo de ambiente.

Esse método foi embasado no seguinte modelo: em que é o índice de confiança (\%), é a média do genótipo i em percentagem, $Z$ é o percentil (1- $\alpha$ ) da função de distribuição normal acumulada, $\operatorname{com} \alpha=$ $0,25, \mathrm{~S}_{\mathrm{i}}$ é o desvio padrão dos valores percentuais. $\mathrm{Na}$ estatística de estabilidade e adaptabilidade $\mathrm{P}_{\mathrm{i}}$, adotada pelo método de Lin \& Binns (1988), é em- 
pregado o quadrado médio da distância entre a média da cultivar e a resposta média máxima obtida no ambiente. A medida de superioridade é obtida por meio do seguinte modelo:

$$
\mathrm{P}_{\mathrm{i}}=\frac{\sum_{\mathrm{j}=1}^{\mathrm{n}}\left(\mathrm{Y}_{\mathrm{ij}-} \mathrm{M}_{\mathrm{j}}\right)^{2}}{2 \mathrm{n}}
$$

onde $P_{i}$ é o índice de estabilidade do genótipo i, $Y_{i j}$ é a produtividade do genótipo i no ambiente j, $M_{j}$ é a produtividade do genótipo com resposta máxima dentre todos no ambiente j, $n$ é o número de ambientes.

A análise de AMMI é uma combinação de métodos univariados (análise de variância) com métodos multivariados (análise de componentes principais e decomposição de valores singulares), combina em um único modelo componentes aditivos para os efeitos principais de genótipos $\left(\mathrm{g}_{\mathrm{i}}\right)$ e de ambientes $\left(\mathrm{a}_{\mathrm{j}}\right)$ e componentes multiplicativos para os efeitos da interação $\left(\mathrm{ga}_{\mathrm{ij}}\right)$ (Duarte \& Vencovsky, 1999).

$y_{i j}=\mu+g_{i}+a_{j}+\sum_{k=1}^{n} \lambda_{k} \gamma_{i k} \alpha_{j k}+\rho_{i j}+\bar{\varepsilon}_{i j}$,

sendo $Y_{i j}$ a resposta média do genótipo i no ambiente $\mathrm{j}, \mu$ a média geral das respostas, $g_{1}$ o efeito fixo do genótipo i $(\mathrm{i}=1,2, \ldots .25), a_{j}$ o efeito fixo do ambiente $\mathrm{j}(\mathrm{j}=1,2, \ldots 8) ; \lambda_{k} \mathrm{o}$ k-ésimo valor singular de GA (escalar), $\gamma_{i k}$ o elemento correspondente ao i-ésimo genótipo no vetor singular $\gamma_{k}$ (vetor singular coluna), $\alpha_{j k}$ o elemento correspondente ao j-ésimo ambiente no vetor $\alpha_{k}$ (vetor singular linha), $\rho_{i j} \mathrm{o}$ resíduo da ACP presente na SQ da interação G x A (porção ruído), $\bar{\varepsilon}_{i j}$ o erro experimental médio, assumido independentemente, $\mathrm{k}$ o índice que se refere aos eixos principais da ACP aplicada à matriz GA. Logo, $k=1,2, \ldots, p$, sendo $p$ o posto da matriz GA, n é o número de eixos ou componentes principais selecionados para descrever o padrão da interação $\mathrm{G}$ x A.

Para Zobel et al. (1988), o método AMMI ( $A d$ ditive Main Effect and Multiplicative Interaction) pro- porciona detalhadamente a análise da interação $\mathrm{G}$ x A por meio do descarte de ruídos adicionais presentes nas estimativas tradicionais da interação, garantindo a seleção de genótipos mais produtivos, propiciando estimativas mais precisas das respostas genotípicas e facilitando a interpretação gráfica dos resultados da análise estatística.

Foi realizado um estudo de correlação de Spearman (Steel \& Torrie, 1960) para comparar os parâmetros de adaptabilidade e estabilidade obtidos pelos métodos testados aplicada às ordens de classificação genotípica, obtidas em cada par de métodos. Os dados obtidos foram analisados utilizando os recursos computacionais do programa Genes (Cruz, 2013).

\section{Resultados e Discussão}

Os efeitos de genótipos, ambientes e genótipos $\mathrm{x}$ ambientes foram significativos $(\mathrm{P}<0,01)$ (Tabela 2). Este fato dificulta a recomendação de cultivares para a região estudada (Cruz \& Castoldi, 1991; Vencovsky \& Barriga, 1992), pois não se pode, nessas circunstâncias, fazer uma recomendação para todos os locais, sem prejuízo considerável na produção. Isso explicita a importância de estudos dos métodos de obtenção das estimativas de adaptabilidade e estabilidade dos genótipos para seleção e recomendação segura de qual híbrido plantar num determinado local. Resultados semelhantes foram encontrados por Silva et al. (2009), que constataram efeito significativo para genótipos, ambientes e para interação para esta característica.

O coeficiente de variação foi inferior a 25\% (Tabela 2) e indicou precisão experimental adequada, segundo classificação proposta por Pimentel-Gomes (2009). A média de produtividade de grãos foi de 5,41 tha-1 ${ }^{-1}$ podendo ser considera satisfatória para a segun- 
da safra. Para esta época, a produtividade nacional é de apenas 2,6 tha-1 ${ }^{-1}$ indicando a necessidade de difusão das tecnologias e cultivares geradas pela pesquisa para aumentar a produtividade de grãos. Vários híbridos apresentaram produtividades similares às duas testemunhas, indicando a possiblidade de lançamento de novos híbridos para estas regiões.

A estimativa dos índices ambientais para a produtividade de grãos apresentados na Tabela 3 demonstram a variação de rendimento verificada entre ambientes, evidenciando a instabilidade nas condições climáticas durante o período estudado. Rio Ver- de, Santo Antônio de Goiás, Sete Lagoas, Sinop e São Gotardo foram classificados como ambientes desfavoráveis e Montividiu, Mata Roma e Vilhena foram classificados como ambientes favoráveis. Não foi possível identificar as causas que contribuíram para o desfavorecimento dos ambientes.

Na Tabela 4, estão contidas as estimativas de adaptabilidade e de estabilidade dos genótipos relativas a cada método. De acordo com o método proposto por Wricke (1965), o genótipo mais estável é aquele que apresenta a menor contribuição para interação genótipos x ambientes. Na Tabela 4, constatou-

Tabela 2. Resumo das análises de variância conjunta, para produtividade de grãos $\left(\mathrm{t}\right.$ ha $\left.{ }^{-1}\right)$, de 25 híbridos de sorgo granífero, cultivados na safrinha de 2012, em oito localidades: Santo Antônio de Goiás, Sete lagoas, Sinop, Vilhena, Mata Roma, Rio Verde, Montividiu e São Gotardo.

\begin{tabular}{cccccc}
\hline \multicolumn{7}{c}{ Produtividade de grãos } \\
\hline F.V. & Blocos/Ambientes & Genótipos $(\mathrm{G})$ & $\begin{array}{c}\text { Ambientes } \\
\text { (A) }\end{array}$ & GxA & Resíduo \\
\hline GL & 16 & 24 & 7 & 168 & 384 \\
Q.M. & 3.05 & $7,25^{* *}$ & $165,19^{* *}$ & $3,12^{* *}$ & 0,82 \\
Média & 5,41 & & & & \\
C.V. $(\%)$ & 16,63 & & & & \\
\hline
\end{tabular}

** Significativo a $1 \%$ de probabilidade.

Tabela 3. Médias de produtividade de grãos em $\mathrm{t}$ ha-1 ${ }^{-1}$ índices ambientais e classificação dos oito ambientes, de 25 híbridos de sorgo granífero, em 2012.

\begin{tabular}{lccl}
\multicolumn{1}{c}{ Ambiente } & Média & Índice & \multicolumn{1}{c}{ Classe } \\
\hline Santo Antônio de Goiás & 5,17 & $-0,24$ & Desfavorável \\
Mata Roma & 5,83 & 0,42 & Favorável \\
Rio Verde & 5,40 & $-0,01$ & Desfavorável \\
Montividiu & 6,76 & 1,35 & Favorável \\
Sete Lagoas & 3,54 & $-1,87$ & Desfavorável \\
Sinop & 5,03 & $-0,38$ & Desfavorável \\
Vilhena & 7,24 & 1,83 & Favorável \\
São Gotardo & 4,59 & $-0,82$ & Desfavorável \\
\hline
\end{tabular}


se que alguns genótipos com menor ecovalência $\left(\mathrm{W}_{\mathrm{i}}\right.$ \%) apresentaram alto rendimento de grãos. Como é o caso dos genótipos 1170036, 1167092 e o 1167048 , que evidenciaram a menor contribuição para interação genótipos $\mathrm{x}$ ambientes e rendimento de grãos acima da média geral. Porém, um dos híbridos mais produtivos (1167053) apresentou vigésimo primeiro valor de ecovalência para produtividade de grãos devido ao conceito de estabilidade pelo método de Wricke (1965) estar associado à invariância ao longo dos ambientes. Observa-se que nem todos os genótipos de maior estabilidade (menor $\mathrm{W}_{\mathrm{i}}$ ) são os que obtiveram alta produtividade de grãos. Resultados semelhantes já foram reportados na literatura (Oliveira et al., 2002; Cargnelutti Filho et al., 2007).

O método proposto por Lin \& Binns (1988)

Tabela 4. Estimativas dos parâmetros de adaptabilidade e estabilidade fenotípica obtidas pelos métodos de Wricke ( $\mathrm{W}_{\mathrm{i}}$ ), análise AMMI (AMMI), Annicchiarico (ANN) e de Lin \& Binns (L\&B) para linhagens de sorgo avaliadas na safra 2012/2013 em Santo Antônio de Goiás, Rio Verde, Montividiu, Mata Roma, Sinop, Sete Lagoas, São Gotardo e Vilhena para a característica de produtividade de grãos.

\begin{tabular}{|c|c|c|c|c|c|c|c|c|c|c|c|c|}
\hline \multicolumn{2}{|c|}{ Genótipo } & \multicolumn{2}{|l|}{ Média } & \multicolumn{3}{|c|}{ ANN } & \multicolumn{3}{|c|}{ L\&B } & \multicolumn{2}{|c|}{ AMMI } & \multirow{2}{*}{$\begin{array}{c}\text { Wricke } \\
\mathrm{W}_{\mathrm{i}}\end{array}$} \\
\hline & & & & $\mathrm{I}_{\mathrm{i}}$ & $\mathrm{I}_{\mathrm{if}}$ & $\mathrm{I}_{\mathrm{id}}$ & $\mathrm{P}_{\mathrm{i}}$ & $P_{i f}$ & $P_{i d}$ & $\mathrm{IPCA}_{1}$ & $\mathrm{IPCA}_{2}$ & \\
\hline 1 & 0307001 & 4.80 & $\mathrm{~b}$ & 87 & 92 & 83 & 3,6 & 2,3 & 5,0 & 0,7 & $-0,1$ & 15,3 \\
\hline 2 & 0307063 & 5.27 & $\mathrm{a}$ & 99 & 94 & 105 & 2,4 & 2,0 & 2,8 & 0,3 & 0,5 & 14,6 \\
\hline 3 & 1167026 & 5.43 & $\mathrm{a}$ & 94 & 99 & 88 & 3,3 & 1,4 & 5,1 & $-0,5$ & $-0,6$ & 15,5 \\
\hline 4 & 0307131 & 4.15 & c & 89 & 97 & 92 & 2,9 & 1,7 & 4,2 & $-0,9$ & $-0,6$ & 47,1 \\
\hline 5 & 0307651 & 5.56 & $\mathrm{a}$ & 89 & 93 & 85 & 3,9 & 2,2 & 5,6 & 0,2 & $-0,1$ & 11,3 \\
\hline 6 & 1167052 & 4.06 & $\mathrm{c}$ & 83 & 93 & 74 & 4,5 & 2,1 & 6,9 & $-0,6$ & $-0,1$ & 17,6 \\
\hline 7 & 0843009 & 5.89 & $\mathrm{a}$ & 95 & 97 & 93 & 3,2 & 1,8 & 4,5 & 0,6 & 0,2 & 19,9 \\
\hline 8 & 0306037 & 5.19 & $\mathrm{a}$ & 107 & 108 & 107 & 2,2 & 0,7 & 3,7 & $-0,2$ & 0,1 & 21,0 \\
\hline 9 & 1096019 & 4.53 & $\mathrm{~b}$ & 75 & 68 & 59 & 6,6 & 6,6 & 6,6 & $-1,2$ & 1,2 & 76,2 \\
\hline 10 & 0307699 & 3,71 & $\mathrm{c}$ & 72 & 87 & 107 & 6,1 & 2,9 & 9,2 & $-0,7$ & $-0,6$ & 20,7 \\
\hline 11 & 1168092 & 4,71 & $\mathrm{~b}$ & 108 & 110 & 88 & 1,3 & 0,6 & 2,1 & 0,2 & 0,1 & 8,2 \\
\hline 12 & 1168093 & 5,67 & $\mathrm{a}$ & 94 & 102 & 101 & 2,9 & 1,1 & 4,8 & 0,8 & $-0,1$ & 21,7 \\
\hline 13 & 0729033 & 5,91 & $\mathrm{a}$ & 95 & 91 & 82 & 2,6 & 2,3 & 2,9 & 0,3 & 0,3 & 8,5 \\
\hline 14 & 1170093 & 4,87 & $\mathrm{a}$ & 91 & 99 & 85 & 3,3 & 1,5 & 5,0 & 0,7 & $-0,2$ & 20,8 \\
\hline 15 & 1167048 & 5,24 & $\mathrm{a}$ & 120 & 97 & 124 & 3,6 & 1,6 & 5,7 & $-0,1$ & $-0,6$ & 10,6 \\
\hline 16 & 1167053 & 5,23 & $\mathrm{a}$ & 103 & 116 & 105 & 1,2 & 0,5 & 1,9 & $-0,8$ & 0,7 & 25,8 \\
\hline 17 & 1167092 & 6,01 & $\mathrm{a}$ & 90 & 102 & 73 & 1,8 & 1,2 & 2,5 & 0,5 & 0,4 & 10,5 \\
\hline 18 & 1167093 & 4,91 & $\mathrm{a}$ & 83 & 94 & 83 & 4,3 & 2,1 & 6,6 & 0,8 & $-0,2$ & 20,4 \\
\hline 19 & 1170019 & 4,06 & $\mathrm{c}$ & 71 & 89 & 57 & 5,4 & 2,6 & 8,3 & $-0,2$ & $-0,9$ & 14,6 \\
\hline 20 & 1170064 & 5,63 & $\mathrm{a}$ & 97 & 103 & 94 & 2,8 & 1,0 & 3,1 & 1,1 & $-0,3$ & 44,4 \\
\hline 21 & 1170090 & 4,82 & $\mathrm{~b}$ & 106 & 106 & 105 & 1,6 & 0,7 & 2,5 & 0,2 & 0,1 & 6,1 \\
\hline 22 & 1170036 & 5,86 & $\mathrm{a}$ & 111 & 98 & 129 & 1,2 & 1,4 & 1,0 & $-0,1$ & 0,6 & 12,6 \\
\hline 23 & 1170026 & 6,65 & $\mathrm{a}$ & 95 & 103 & 87 & 3,4 & 1,1 & 5,7 & $-0,7$ & $-1,0$ & 37,9 \\
\hline 24 & BRS330 & 5,22 & $\mathrm{a}$ & 102 & 96 & 112 & 1,8 & 1,8 & 1,7 & $-0,1$ & 0,4 & 12,3 \\
\hline 25 & DKB550 & 5,87 & $\mathrm{a}$ & 99 & 92 & 106 & 2,5 & 2,1 & 2,9 & $-0,2$ & 0,3 & 10,7 \\
\hline
\end{tabular}

Médias seguidas por letras iguais não diferem entre si, pelo teste Scott-Knott, a 5\% de probabilidade. 
permite quantificar o quanto a cultivar está próxima do desempenho ideal, referenciado como sendo o de um híbrido com a maior produtividade em todos os ambientes estudados. Na Tabela 4, estão apresentados os valores de $\mathrm{P}_{\mathrm{i}}$ para todos os ambientes dos 25 genótipos de sorgo granífero. Verificou-se que os quatro híbridos que mais se destacaram foram 1167053, 1170036, 1168092 e 1167092; apresentaram os menores valores de $\mathrm{P}_{\mathrm{i}}$ geral, ou seja, maior estabilidade. Porém, o genótipo 1168092 apresenta baixo rendimento de grãos.

No método de Annicchiarico, os genótipos 1167048, 1170036, 1168092 e 0306037 apresentaram menores riscos de possuírem comportamento abaixo da média geral para o rendimento dos grãos. O híbrido 1167048 apresenta-se mais responsivo às melhorias do ambiente. Nos métodos estudados, existe um grau de associação; ainda assim, não garante concordância geral entre eles, sendo que $10 \%$ das correlações estimadas apresentaram significância estatística (Tabela 5). Silva \& Duarte (2006) fizeram uma comparação de várias metodologias em estudo de adaptabilidade e estabilidade em soja em Goiás e concluíram que o uso do método de Wricke foi contraindicado. Aos métodos Annicchiarico e Lin \& Binns, que implicam classificações fenotípicas muito semelhantes. Métodos baseados exclusivamente em coeficientes de regressão devem ser utilizados em associação com outro, fundamentado na variância da interação G x A ou em medidas estatísticas, como a variância dos desvios da regressão.

Comparando o método de Wricke (1965) com a média ( $r s=0.0123$ ), observou-se correlação fraca e positiva (Tabela 5), o que indica haver indivíduos produtivos com alta contribuição para interação, sugerindo uma possível adaptabilidade específica e, também, haver indivíduos produtivos com adaptabilidade geral, indicando uma tendência de serem considerados estáveis pelo método de Wricke (1965). Esse resultado é incomum na literatura, uma vez que, geralmente, são observadas correlações menores e, estatisticamente, nulas (Silva \& Duarte 2006; Cargnelutti Filho et al., 2007; Silva Filho et al., 2008; Scapim et al. 2010; Vilela et al., 2011).

Os métodos de Annicchiarico (1992) e de Lin \& Binns (1988) são interessantes por utilizarem a média como um dos parâmetros mais participativos para estimativa da adaptabilidade e da estabilidade; porém, o uso concomitante dos métodos foi contraindicado, dado que exibiram alta associação ( $r$ s $=0,648$ ), o que implica classificações fenotípicas muito semelhantes. Entretanto, o uso de um deles é recomendado. Esses

Tabela 5. Estimativas do coeficiente de correlação de Spearman aplicado às ordens de adaptabilidade e estabilidade de cada par de métodos.

\begin{tabular}{ccccc}
\hline Método & Lin \& Binns & AMMI & Wricke & Média \\
\hline Annicchiarico & 0,687 & 0,251 & 0,068 & 0,028 \\
Lin \& Binns & & $0,436^{*}$ & 0,228 & 0,042 \\
AMMI & & 0,394 & 0,202 \\
Wricke & & & $-0,117$ \\
\hline
\end{tabular}

* Significativo a $5 \%$ de probabilidade. 
métodos possibilitam uma interpretação mais fácil, baseada na análise de apenas um parâmetro, o que também possibilita o ranqueamento dos genótipos mais adaptados e estáveis.

O método AMMI se correlacionou com a maior parte dos métodos. A associação mais representativa foi apresentada com os métodos de Wricke $(\mathrm{rs}=0.394)$ e de Lin \& Binns ( $\mathrm{rs}=0.436)$. O modelo AMMI integra a análise de variância com a técnica de componentes principais, sendo que, segundo Silva \& Duarte (2006), apresentando princípios semelhantes aos métodos de Wricke (1965); porém, o método AMMI possui vantagens estatísticas, pois permite eliminar ruídos na interação $\mathrm{G}$ x A, estimada por esses métodos. Com tal característica, essa análise apresenta-se como um método mais apropriado a esses estudos. Observa-se que o método de Lin \& Binns (1988) mostrou uma associação significativa com a análise AMMI. Resultados semelhantes foram observados por Silva \& Duarte (2006), que também observaram que esses métodos, de alguma maneira, se complementam, sendo que o método de Lin \& Binns, em detrimento da análise AMMI, informa sobre a resposta de cada genótipo diante da melhoria ambiental. Porém, o método AMMI gera uma estimativa da contribuição genotípica, para a interação G x A, com ausência de ruídos, que o método de Lin \& Binns não descarta.

Para compreender os resultados do método AMMI, Purchase et al. (2000) recomendaram um índice de estabilidade, considerando os dois primeiros componentes principais do modelo. Pela análise do índice IPCA e IPCA $_{2}$, observou-se que os híbridos 1167048, 1170036, 1168092 e 1170090 foram os que mais se aproximaram da origem (Figura 1), indicando que o desempenho desses materiais foi estável, uma vez que esses contribuíram pouco para a interação $\mathrm{G}$ x A. Silva \& Duarte (2006) também observaram correlação entre os postos do método de Wricke (1965) a IPC $\Delta 1$

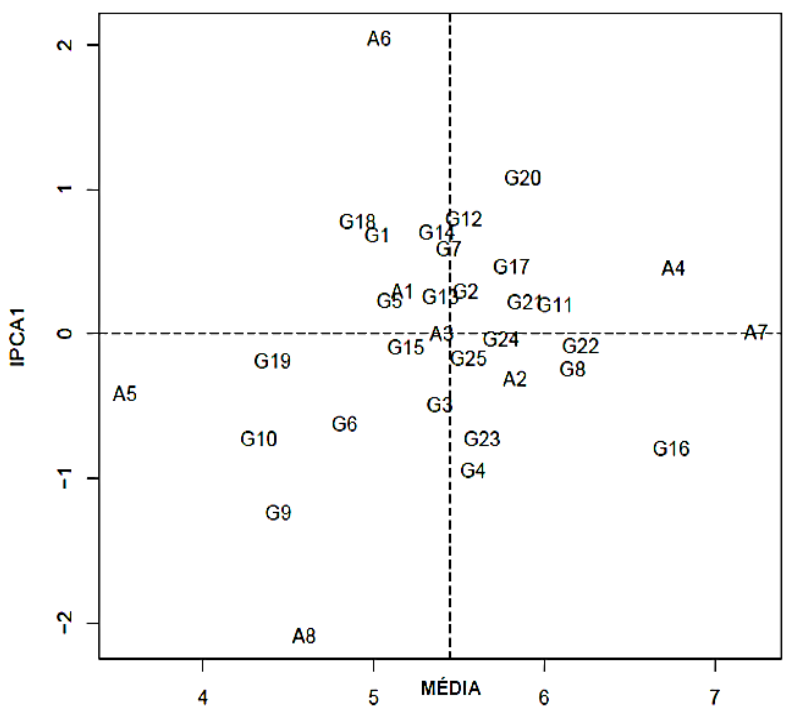

Figura 1. Plotagem do $\mathrm{IPCA}_{1}$ e média de produtividade de grãos de sorgo granífero, quanto à indicação dos oito locais de semeadura, segundo o modelo AMMI. As codificações dos híbridos estão de acordo com a Tabela 4, em ordem crescente. A1 (GO): Santo Antônio de Goiás; A2 (MR): Mata Roma; A3 (RV): Rio Verde; A4 (MON): Montividiu; A5 (SL): Sete Lagoas; A6 (SIN): Sinop; A7 (VIL): Vilhena; A8 (SG): São Gotardo.

Os primeiros componentes AMMI assimilam maior percentagem do desempenho real padrão e, com acumulação de componentes, consequentemente diminuição na percentagem de padrão e acréscimo de informações inconsistentes (ruídos). A análise da interação genótipos x ambientes, pelos componentes principais, mostrou que o primeiro IPCA explicou $44,01 \%$ da soma dos quadrados devido à interação genótipo por ambiente. Os dois primeiros componentes principais, em conjunto, explicaram $65,15 \%$ da soma dos quadrados devido à interação genótipos $\mathrm{x}$ 
ambientes.

Os resultados desse estudo indicam que o uso de um desses métodos em combinação, por exemplo, com o de AMMI, pode fornecer informações adicionais e complementares sobre a estabilidade fenotípica em sorgo. A interpretação da estabilidade pelo modelo AMMI foi analisada de acordo com a distância dos pontos representativos dos 25 genótipos em relação à produtividade de grãos em oito ambientes. Assim, os pontos que pouco contribuem para a interação representam menor distância, indicando maior estabilidade.

A adaptabilidade dos genótipos em cada local de cultivo é interpretada observando-se os sinais dos escores para genótipos e ambientes, visto que genótipos e locais com escores de mesmo sinal interagem positivamente (Duarte \& Vencovsky, 1999), indicando em qual local o genótipo deve ser preferencialmente cultivado. Genótipos e ambientes mais estáveis são aqueles cujos pontos se aproximam da origem, ou seja, com escores praticamente nulos para os dois eixos da interação (Duarte \& Vencovsky, 1999). Pela análise gráfica de AMMI, pode-se observar que os genótipos classificados estatisticamente como os mais produtivos pelo teste de Scott-Knott foram os que menos se distanciaram da origem, sendo considerados estáveis. Os ambientes Santo Antônio de Goiás, Rio Verde e Montividiu apresentaram padrão de respostas similares e estão localizados na área mais próxima da origem em relação aos demais ambientes, sendo considerados com alta estabilidade. Os ambientes que atestam baixa estabilidade foram São Gotardo e Sinop.

A estabilidade ambiental informa sobre a confiabilidade das posições dos genótipos (postos) em cada ambiente em relação à classificação para a média dos ambientes testados. Nesse contexto, as discrepâncias menores foram verificadas para os locais Santo Antônio de Goiás e Rio Verde, em relação aos outros locais. Isso sugere que a classificação dos genótipos nesses ambientes deveria apresentar discordâncias pequenas em relação à classificação média em todos os locais. Os genótipos 1170064, 1096019 e 1167053 foram os que mais se distanciaram da origem, sendo os genótipos que mais contribuíram para a interação $\mathrm{G} \times \mathrm{A}$ e, consequentemente, atestando a instabilidade dessas cultivares.

As análises realizadas com os métodos de Lin \& Binns e de Annicchiarico apresentam elevada aproximação entre si e produzem classificações genotípicas similares quanto à estabilidade fenotípica; desta forma, o uso simultâneo dos dois não é recomendado. Entretanto, o uso do método de Annicchiarico em combinação com AMMI pode agregar informação à análise de estabilidade. Dessa forma, estes métodos apresentam resposta mais fácil e apropriada para as recomendações e o método de AMMI serviu como informação complementar sobre o comportamento dos genótipos.

\section{Conclusões}

Os métodos AMMI e Wricke (1965) podem ser utilizados de forma complementar na recomendação dos genótipos devido a sua baixa correlação.

Os híbridos 1170036, 1167048 e 1170064 se destacaram por possuírem desempenho superior, alta adaptabilidade e estabilidade, podem ser alternativas para futura recomendação para cultivo em ambas as regiões.

\section{Referências}

ANNICCHIARICO, P. Cultivar adaptation and recommendation from alfafa trials in Northern Italy. Journal of Genetics and Breeding, Roma, n. 1, v. 46, p. 269-278, 1992. 
CARGNELUTTI FILHO, A.; PERECIN, D.; MALHEIROS, E. B.; GUADAGNIN, J. P. Comparação de métodos de adaptabilidade e estabilidade relacionados à produtividade de grãos de cultivares de milho. Bragantia, Campinas, v. 66, n. 4, p. 571-578, 2007.

DOI: $10.1590 /$ S0006-87052007000400006.

CRUZ, C. D. GENES: a software package for analysis in experimental statistics and quantitative genetics. Acta Scientiarum. Agronomy, Maringá, v. 35, n. 3, p. 271-276, 2013. DOI: $10.4025 /$ actasciagron.v35i3.21251.

CRUZ, C. D.; CARNEIRO, P. C. S. Modelos biométricos aplicados ao melhoramento genético. Viçosa, MG: UFV, 2003. 585 p.

CRUZ, C. D.; CASTOLDI, F. L. Decomposição da interação genótipos x ambientes em partes simples e complexa. Revista Ceres, Viçosa, MG, v. 38, n. 219, p. 422-430, 1991.

DUARTE, J. B.; VENCOVSKY, R. Interação genótipos x ambientes: uma introdução à análise "AMMI". Ribeirão Preto: Sociedade Brasileira de Genética, 1999. 60 p. Disponível em: <https://agro.ufg.br/up/68/o/Monografia_AMMIGXE_Rev_2007_2.pdf $>$. Acesso em: 13 maio 2016.

IBGE. Levantamento sistemático da produção agrícola. Rio de Janeiro, 2014.

LIN, C. S.; BINNS, M. R. A superiority measure of cultivar performance for cultivar $\mathrm{x}$ location data. Canadian Journal of Plant Science, Ottawa, v. 68, p. 193-198, 1988.

OLIVEIRA, J. S.; FERREIRA, R. P.; CRUZ, C. D.; PEREIRA, A.V.; BOTREL, M. A.; VON PINHO, R. G.; RODRIGUES, J. A. S.; LOPES, F. C. F.; MIRANDA, J. E. C. Adaptabilidade e estabilidade em cultivares de sorgo. Revista Brasileira de Zootecnia, Viçosa, v. 31, n. 2, p. 883-889, 2002.

PIMENTEL-GOMES, F. Curso de estatística experimental. 15. ed. Piracicaba: ESALQ, 2009. 451 p. (Biblioteca de Ciências Agrárias Luiz de Queiroz, 15).
PURCHASE, J. L.; HATTING, H.; VAN DEVENTER, C. S. Genotype $x$ environment interaction of winter wheat in south Africa: II. Stability analysis of yield performance. South African Journal of Plant and Soil, Ottawa, v. 17, p. 101-107, 2000. DOI: $10.1080 / 02571862.2000 .10634878$.

RAMALHO, M. A. P.; ABREU, A. F. B.; SANTOS, J. B.; NUNES, J. A. Aplicações da genética quantitativa no melhoramento de plantas autógamas. Lavras: UFLA, 2012. $512 \mathrm{p}$

ROONEY, W. Sorghum Breeding. In: ACQUAAH, G. (Ed.). Principles of plant genetics and breeding. Malden: Blackwell Publishing, 2007, cap. 30, p. 509-518.

SANTOS, F. G.; CASELA, C. R.; WAQUIL, J. M. Melhoramento de sorgo. In: BORÉM, A. (Org.). Melhoramento de espécies cultivadas. 2. ed. Viçosa, MG: UFV, 2005. v. 1, p. 429-466.

SCAPIM, C. A.; PACHECO, C. A. P.; AMARAL JÚNIOR, A. T.; VIEIRA, R. A.; PINTO, R. J. B.; CONRADO, T. V. Correlations between the stability and adaptability statistics of popcorn cultivars. Euphytica, Wageningen, v. 174, n. 2, p. 209-218, 2010.

DOI: 10.1007/s10681-010-0118-y.

SILVA, A. G.; BARROS, A. S.; SILVA, L. H. C. P.; MORÃES, E. B.; PIRES, R.; TEIXEIRA, I. R. Avaliação de cultivares de sorgo granífero na safrinha no sudoeste do Estado de Goiás. Pesquisa Agropecuária Tropical, Goiânia, v. 39, n. 2, p. 168-174, 2009.

SILVA, W. C. J.; DUARTE, J. B. Métodos estatísticos para estudo de adaptabilidade e estabilidade fenotípica em soja. Pesquisa Agropecuária Brasileira, Brasília, DF, v. 41, n. 1, p. 23-30, 2006.

DOI: $10.1590 / \mathrm{S} 0100-204 X 2006000100004$.

SILVA FILHO, J. L.; MORELLO, C. L.; FARIAS, F. J. C.; LAMAS, F. M.; PEDROSA, M. B.; RIBEIRO, F. L. Comparação de métodos para avaliar a adaptabilidade e estabilidade produtiva em algodoeiro. Pesquisa Agropecuária Brasileira, Brasília, DF, v. 43, n. 3, p. 349-355, 2008. 
DOI: 10.1590/S0100-204X2008000300009.

STEEL, R. G. D.; TORRIE, J. H. Principles and procedures of statistics. New York: McGraw -Hill, 1960. 481 p. VENCOVSKY, R.; BARRIGA, P. Genética biométrica no fitomelhoramento. Ribeirão Preto: Sociedade Brasileira de Genética, 1992. 496 p.

VILELA, F. O.; AMARAL JÚNIOR, A. T.; GONÇALVES, L. S. A.; BARBÉ, T. C.; GRAVINA, G. A. Stability of F7:8 snap bean progenies in the Northern and Northwestern regions of Rio de Janeiro State. Horticultura Brasileira, Brasília, DF, v. 29, n. 1, p. 84-90, 2011.

DOI: $10.1590 / \mathrm{S} 0102-05362011000100014$.

WRICKE, G. Zur Berechnung der Ökovalenz bei Sommerweizen und Hafer. Pflanzenzuchtung, v. 52, n. 1, p. 127-138, 1965.

ZOBEL, R. W.; WRIGHT, M. J.; GAUCH, H. G. Statistical analysis of a yield trial. Agronomy Journal, Madison, v. 80 , p. 388-393, 1988.

DOI: 10.2134/agronj1988.00021962008000030002x. 